\title{
Case report: a combination of neurological and hematological manifestations in a I4y old female
}

\begin{abstract}
A 14years old female presented with 10days history of headache, abdominal pain, lethargy and fever. Her CBC showed only anemia and she only received symptomatic and supportive treatment. however the patient gradually developed unexpected neurological manifestations like loss of speech, hypotonia and weakness of both upper and lower limbs, she can no longer walk nor sit .few days later her $\mathrm{CBC}$ showed pancytopenia with ANC 448 and platelets 7000 HB 7, Bone Marrow Biopsy was Norm cellular with Grade 2 Fibrosis. Liver enzymes elevated ALT 304, reticulocytosis, coombs test negative, all the imaging to brain and spine were normal including CT and MRI. ANA anti DNA negative, ferrittin over 3000, viral markers for EBV, CMV, Hepatitis A,B,C Parvovirus B19 all negative. The patient considered atypical case of $\mathrm{HLH}$ and received 2 weeks course of steroids and gradual improvement of the $\mathrm{CBC}$ and neurological condition began.
\end{abstract}

Volume 2 Issue 6 - 2015

\author{
Sahbaa Fehr Mohamed Hafez \\ Department of Pediatrics, Zagazig University, Egypt
}

Correspondence: Sahbaa Fehr Mohamed Hafez, Department of Pediatrics, assistant lecturer, Zagazig University, I0th Ramadan city, mogawra 9, villa 224, Egypt, Tel 01006533459,0 I 208 I I 2002, Email sahbaafehr@yahoo.com

Received: June 18,2015 | Published: September 8, 2015

Keywords: pancytopenia, bone marrow biopsy, neurological, HLH

Abbreviations: $\mathrm{CBC}$, complete blood count; $\mathrm{ANC}$, absolute neutrophilic count; ALT, alanine transaminase; MRI, magnetic resonance imaging; CT, computed tomography; ANA, antinuclear antiboby; EBV, ebstien bar virus; CMV, cytomegalo virus; HLH, hemophagocyic lymphohistioctosis

\section{Introduction}

It's a case of atypical HLH which doesn't have all the criteria of the classic cases, this is a previously completely normal 14years old female presenting to us with pancytopenia and acute dramatic weakness and hypotonia in all her limbs and trunk .she also lost her speech and only could produce sounds now. she had no sphincteric control loss her co ordination could not really be assessed due to marked weakness of her limbs, her cranial nerves however were not affected negative Babiniski with preserved abdominal reflexes. System review other than that was normal. ${ }^{1}$ Bone marrow biopsy was cellular with fibrosis and brain and spinal imaging was normal, abdominal ultrasound showed moderately enlarged spleen. ${ }^{2}$ Blood tests showed pancytopenia with mild reticulocytosis but no hyperbilirubinemia, elevated liver enzymes, normal albumin, very high ferrittin level, normal soluble $\mathrm{CD} 25$, cerebrospinal fluid examination was normal excluding CNS infection, all viral markers were normal, lipid profile was normal. ${ }^{3,4}$

\section{Discussion}

This was a very confusing case with acute onset of dramatic manifestations and no clear explanation, as only the neurological system and hematological system were involved we thought of either viral infection specially CMV and HLH, as viral markers and CMV PCR were negative and the new diagnostic modified criteria of HLH required less than 4 the patient received steroid therapy and her condition both the $\mathrm{CBC}$ and neurological improved gradually within 2 weeks of therapy. ${ }^{4-6}$ Hemophagocytic lymphohistiocytosis (HLH) is a rare but potentially fatal disease of normal but overactive histiocytes and lymphocytes that commonly appears in infancy, although it has been seen in all age groups. ${ }^{6,7}$ The pathological hallmark of this disease is the aggressive proliferation of activated macrophages and histiocytes, which phagocytose other cells, namely RBCs, WBCs and platelets, leading to the clinical symptoms. ${ }^{8}$ The uncontrolled growth is nonmalignant and does not appear clonal in contrast to the lineage of cells in Langerhans cells histiocytosis (histiocytosis X). The spleen, lymph nodes, bone marrow, liver, skin and membranes that surround the brain and spinal cord are preferential sites of involvement. This disorder may be viewed as a highly stimulated, but ineffective, immune response to antigens, which results in life-threatening cytokine storm and inflammatory reaction. ${ }^{7-9}$

The diagnosis of HLH may be established by

A. A molecular diagnosis consistent with HLH (For example, pathologic mutations of PRF1, UNC13D or STX11 are identified)

Or

i. Fulfillment of five out of the eight criteria listed below:

ii. Fever

iii. Splenomegaly

iv. Cytopenias (affecting at least two of three lineages in the peripheral blood):

v. Hemoglobin $<9 \mathrm{~g} / 100 \mathrm{ml}$ (in infants <4weeks: hemoglobin $<10 \mathrm{~g} / 100 \mathrm{ml})$

vi. Platelets $<100$ times $103 / \mathrm{ml}$

vii. Neutrophils $<1$ times $103 / \mathrm{ml}$

viii. Hypertriglyceridemia (fasting, greater than or equal to $265 \mathrm{~m}$ $\mathrm{g} / 100 \mathrm{ml}$ ) and/or hypofibrinogenemia (less than or equal to $150 \mathrm{mg} / 100 \mathrm{ml}$ )

ix. Hemophagocytosis in BM, spleen or lymph nodes

x. Low or absent NK cell activity

xi. Ferritin greater than or equal to500ng/ml 
xii. Soluble CD25 (that is, soluble IL-2 receptor) $>2400 \mathrm{U} / \mathrm{ml}$ (or per local reference laboratory)

Ideally, the diagnosis of HLH is based upon fulfilling the published diagnostic criteria used in the HLH-2004 trial, not infrequently; however, a diagnosis of HLH is made in the patient who only partly meets the most stringent criteria because definitive HLH therapy must be initiated due to an inadequate response to general supportive care. ${ }^{8}$ A presumptive diagnosis depends upon a careful consideration of the presence or absence of the specific elements of the diagnostic criteria, the results of additional laboratory tests (eg, D-dimer and liver function tests) and a nuanced view of the overall clinical status. Here our patient had spleenomegaly, pancytopenia and fever meeting the diagnostic criteria, very high ferrittin level however her bone marrow was missing the haemophagocytotic picture, normal soluble CD 25 and normal lipid profile. ${ }^{9}$ Our patient started treatment initially with etoposide and dexamethasone for 8 weeks and she showed dramatic response regarding the neurological symptoms and the pancytopenia with fever coming to control. The patient was on close follow up in our hematology clinic for any signs of infection or malignant transformation.

\section{Acknowledgements}

None.

\section{Conflict of interest}

The author declares no conflict of interest.

\section{References}

1. Henter JI, Horne A, Aricó M, et al. HLH-2004: Diagnostic and therapeutic guidelines for hemophagocytic lymphohistiocytosis. Pediatr Blood Cancer. 2007;48(2):124-131.

2. Larroche C. Hemophagocytic lymphohistiocytosis in adults: diagnosis and treatment. Joint Bone Spine. 2012;79(4):356-361.

3. Tang Y, Xu XJ. Advances in hemophagocytic lymphohistiocytosis:pathogenesis, early diagnosis/differential diagnosis, and treatment. Scientific World Journal. 2011;11:697-708.

4. Arico M, Danesino C, Pende D, et al. Pathogenesis of haemophagocytic lymphohistiocytosis. Br J Haematol. 2001;114(4):761-769.

5. Aricò M, Janka G, Fischer A, et al. Hemophagocytic lymphohistiocytosis. Report of 122 children from the international registry. FHL study group of the histiocyte society. Leukemia. 1996;10(2):197-203.

6. Henter JI, Elinder G, Ost A. Diagnostic guidelines for hemophagocytic lymphohistiocytosis. The FHL study group of the histiocyte society. Semin Oncol. 1991;18(1):29-33.

7. Henter JI, Elinder G, Soder O, et al. Incidence in Sweden and clinical features of familial hemophagocytic lymphohistiocytosis. Acta Paediatr Scand. 1991;80(4):428-435.

8. Saeed H, Woods RR, Lester J, et al. Evaluating the optimal serum ferritin level to identify hemophagocytic lymphohistiocytosis in the critical care setting. Int J Hematol. 2015;102(2):195-199.

9. Lymphohistiocytosis, Hemophagocytic at the US national library of medicine medical subject headings (MeSH);1999. 